Disclosure of Interests: Cristina Solé-Marcé: None declared, Ana Maria Alvarez-Rios: None declared, Teresa Moline: None declared, Berta Ferrer: None declared, Josep Ordi-Ros: None declared, Josefina Cortés-Hernández Grant/research support from: GSK, Speakers bureau: GSK DOI: 10.1136/annrheumdis-2019-eular.7999

\section{THU0211 EVOLUTION OF KIDNEY ANTIBODY SECRETING CELLS MOLECULAR SIGNATURE IN LUPUS PATIENTS WITH ACTIVE NEPHRITIS UPON IMMUNOSUPPRESSIVE THERAPY}

Etienne Crickx ${ }^{1,2}$, Farah Tamirou ${ }^{3,4}$, Tessa Huscenot ${ }^{5}$, Nathalie CostedoatChalumeau $^{6}$, Marion Rabant ${ }^{7}$, Alexandre Karras ${ }^{8}$, Ailsa Robbins ${ }^{9}$, Tatiana Fadeev ${ }^{1}$, Véronique Le Guern ${ }^{6}$, Philippe Remy ${ }^{10}$, Aurélie 'Hummel ${ }^{11}$ Bertrand Godeau ${ }^{2}$, Bernard Lauwerys ${ }^{3,4}$, Jean-Claude Weill ${ }^{1}$, ClaudeAgnès Reynaud ${ }^{1}$, Frederic Houssiau ${ }^{3,4}$, Matthieu Mahévas ${ }^{1,2} .{ }^{1}$ Institut Necker Enfants Malades, INSERM U1151/CNRS UMS 8253, Paris, France; ${ }^{2}$ Hôpital Henri-Mondor (APHP), Department of Internal Medicine, Créteil, France; ${ }^{3}$ Cliniques Universitaires Saint-Luc, Service de Rhumatologie, Brussels, Belgium; ${ }^{4}$ Université de Louvain, Pôle de Pathologies Rhumatismales Inflammatoires et Systémiques, Brussels, Belgium; ${ }^{5}$ Hôpital Lariboisière (APHP), Department of Internal Medicine, Paris, France; ${ }^{6}$ Cochin Hospital (APHP), Internal Medicine Department, Paris, France; ${ }^{7}$ Necker Hospital (APHP), Pathology Department, Paris, France; ${ }^{8}$ Hôpital Européen Georges-Pompidou (APHP), Department of Nephrology, Paris, France; ${ }^{9}$ Robert Debré Hospital, Department of Internal Medicine, Reims, France; ${ }^{10}$ Hôpital Henri-Mondor (APHP), Department of Nephrology, Créteil, France; ${ }^{11}$ Necker Hospital (APHP), Nephrology Department, Paris, France

Background: Pathogenic antibody secreting cells (ASC) have been identified in the kidney of SLE-prone mice, but are poorly characterized in human lupus nephritis (LN). We hypothesized that long-lived plasma cells may contribute to the failure of immunosuppressive therapy in refractory patients.

Objectives: To characterize and compare the single cell molecular signature of ASC in kidney and urine from patients with active $L N$, either untreated or after immunosuppressive therapy failure.

Methods: We included patients with biopsy proven active LN from 4 centers and meeting the ACR revised classification criteria for SLE diagnosis. Renal biopsies were scored according to 2003 International Society of Nephrology/Renal Pathology Society (ISN/RPS) classification, and stained with anti-CD138 to visualize ASC. ASC were single cell sorted as CD3-/ CD14-/CD16-/CD27 ${ }^{\text {high }} / C D 38^{\text {high }}$ cells. Single-cell gene expression profiling was performed by multiplex RT-PCR using Fluidigm Dynamic Arrays. We used a set of genes derived from a previous transcriptomic analysis of human splenic and bone marrow ASC to distinguish the process of ASC maturation from plasmablast (PB) to long-lived PC. We also studied ASC transcriptional program from urine of untreated $L N$ patients at diagnosis and after 3 and 6 months of a prospective follow up during induction therapy (Plasmo-Lup study).

Results: Immunohistochemistry stainings on kidney biopsies from both untreated $(\mathrm{N}=15)$ and refractory patients $(\mathrm{N}=6)$ showed infiltrates of CD138+ ASC mainly located in the interstitium, particularly in untreated patients. Single cell molecular signature of kidney ASC from 3 untreated patients with class IV LN revealed that these cells were mostly PB expressing multiple genes linked with cell division, and PC without longlived genes expression. This contrasted with ASC signature from 3 patients with active $L N$ and mycophenolate mofetil (MMF) failure that expressed long-lived PC genes and no proliferative genes. Primary component analysis of 170 single-cells showed clustering of ASC from MMF treated patients with long-lived bone marrow PC from healthy donors that were distinct from $\mathrm{PB} / \mathrm{PC}$ from untreated patients (Figure 1). A PB signature was observed in urine ASC at diagnosis, similar to their kidney counterpart. The concentration of ASC in urine in 22 untreated patients correlated with ISN/RPS classification, with higher concentration in class IV patients $(\mathrm{p}<0.01)$.

Conclusion: These results suggest that PB infiltrate kidney of untreated LN patients, and that kidney long-lived PC may contribute to the failure of immunosuppressive therapy.

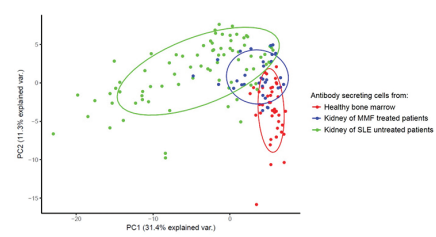

Abstract THU0211 - Figure 1. Single cell principal component analysis of 170 individual cells analyzed for the expression of 20 genes. Each dot represents a single cell.

Acknowledgement: This work was supported by Foreum Disclosure of Interests: None declared

DOI: 10.1136/annrheumdis-2019-eular.4739

\section{THU0212 BARICITINIB-ASSOCIATED CHANGES IN GLOBAL GENE EXPRESSION DURING A 24-WEEK PHASE 2 CLINICAL SLE TRIAL DESCRIBE A MECHANISM OF ACTION THROUGH INHIBITION OF JAK/STAT AND IFN RESPONSIVE GENE EXPRESSION}

Thomas Dörner ${ }^{1}$, Yoshiya Tanaka ${ }^{2}$, Michelle A Petri $^{3}$, Josef S. Smolen ${ }^{4}$ Ernst Dow ${ }^{5}$, Richard E Higgs ${ }^{5}$, Guilherme Rocha ${ }^{5}$, Robert Benschop ${ }^{5}$, Maria Silk ${ }^{5}$, Stephanie de Bono ${ }^{5}$, Robert Hoffman ${ }^{5}$. ${ }^{1}$ Charite Universitätsmedizin Berlin and Deutsches Rheumaforschungszentrum (DRFZ), Berlin, Germany; ${ }^{2}$ Univ of

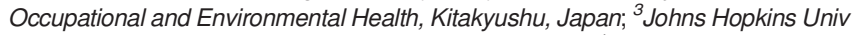
School of Medicine, Baltimore, United States of America; ${ }^{4}$ Medical Univ of Vienna, Vienna, Austria; ${ }^{5}$ Eli Lilly and Company, Indianapolis, United States of America

Background: Baricitinib (bari) is an oral selective Janus kinase (JAK) 1 and JAK2 inhibitor. In the Phase 2 study, JAHH (NCT02708095), treat ment with bari resulted in significant improvements in patients (pts) with active systemic lupus erythematosus (SLE) receiving standard background therapy, compared with placebo (PBO). ${ }^{1}$

Objectives: To use global gene expression to characterize baseline (BL) gene expression among SLE pts in JAHH and to describe the mechanism of action (MoA) of bari during treatment in active SLE.

Methods: A total of 314 pts were randomized 1:1:1 to PBO, bari 2-mg, or bari 4-mg once daily for 24 weeks (Wks) in JAHH. RNA isolated from whole blood at $\mathrm{BL}$ and Wks 2, 4, 12, and 24 was analyzed using HTA2.0 arrays, possessing over 925,000 specific individual probes. Data were summarized to transcript level and analyzed using a mixed effects model on a log2 transformed response with multiplicity correction.

Results: Baseline gene expression analysis comparing healthy controls to SLE pts revealed elevated expression of genes involved in innate and adaptive immune pathways and biologic processes thought to be key to SLE pathogenesis. Baseline findings from the ILLUMINATE trial of tabalu mab (1760 SLE pts at $B L)^{2}$ were independently replicated, including individual gene-specific changes in the SLE populations versus controls. Treatment-induced changes were predominantly observed in the bari 4-mg versus PBO group at early time points (Wks 2 and 4; bari 4-mg > 2$\mathrm{mg}$ ). Statistically significant changes were observed for type I and II IFN responsive genes, and in the $\mathrm{JAK} /$ signal transducer and activator of transcription (STAT) canonical and noncanonical signaling pathways, in the bari 4-mg versus PBO group comparisons. There were biologically notable and statistically significant bari-associated decreases in gene expression from $\mathrm{BL}$, compared to $\mathrm{PBO}$, for interleukin (IL)-3, -5, -6, -7, and granulocyte macrophage colony-stimulating factor pathways, attributable to inhibition of JAK/STAT signaling.

Conclusion: These results build upon previous studies of gene expression in ILLUMINATE, comparing SLE at $\mathrm{BL}$ with healthy controls; they advance our understanding of lupus pathogenesis, and further delineate the MoA of bari in SLE. These data independently confirm the marked elevations of specific type I and II IFN genes at BL in clinical trial pts on standard of care treatment. Changes in gene expression with bar impacted IFN responsive genes as well as JAK/STAT signaling pathways. Interpretation of results is limited by sample size and statistical power and presence of concomitant medications. Importantly, gene expression may not translate directly to protein expression; however, ongoing proteo mic studies (including specific assays for type I IFN, IFN- $\gamma$, IL-12, IL-17, and IL-23) will help extend these gene expression results and further describe the MoA of bari in SLE.

REFERENCES:

[1] Wallace D, et al. Lancet. 2018;392:222-231

[2] Hoffman R, et al. Arthritis Rheumatol. 2017;69:643-654 
Disclosure of Interests: Thomas Dörner Grant/research support from: Eli Lilly, Janssen, Roche, UCB Pharma, Consultant for: Eli Lilly, Janssen, Roche, UCB Pharma, Speakers bureau: Eli Lilly, Janssen, Yoshiya Tanaka Grant/research support from: Abbvie, Astellas, Bristol-Myers Squibb, Chugai, Daiichi-Sankyo, Eisai, Mitsubishi-Tanabe, MSD, Ono, Taisho-Toyama, Takeda, Speakers bureau: Abbvie, Asahi-kasei, Astellas, Bristol-Myers Squibb, Chugai, Daiichi-Sankyo, Eli Lilly, Eisai, Glaxo-Smithkline, Janssen, Mitsubishi-Tanabe, Novartis, Pfizer Japan Inc, Sanofi, Takeda, UCB, YL Biologics, Michelle A Petri Shareholder of: Pfizer, Merck, Grant/research support from: AstraZeneca, Exagen, Consultant for: Eli Lilly, GSK, Merck EMD Serono, Janssen, Amgen, Novartis,

Quintiles, Exagen, Inova Diagnostics, AstraZeneca, Blackrock,

Glenmark, UCB, and the Annenberg Center for Health Sciences, Josef S. Smolen Grant/research support from: AbbVie, Eli Lilly, Janssen, MSD, Pfizer Inc, Roche, Consultant for: AbbVie, Amgen, AstraZeneca, Astro, Celgene, Celtrion, Eli Lilly, GlaxoSmithKline, ILTOO, Janssen, Medimmune, MSD, Novartis-Sandoz, Pfizer Inc, Roche, Samsung, Sanofi, UCB, Speakers bureau: AbbVie, Amgen, AstraZeneca, Astro, Celgene, Celtrion, Eli Lilly, GlaxoSmithKline, ILTOO, Janssen, Medimmune, MSD, Novartis-Sandoz, Pfizer Inc, Roche, Samsung, Sanofi, UCB, Ernst Dow Shareholder of: Eli Lilly and Company, Employee of: Eli Lilly and Company, Richard E Higgs Shareholder of: Eli Lilly and Company, Employee of: Eli Lilly and Company, Guilherme Rocha Shareholder of: Eli Lilly and Company, Employee of: Eli Lilly and Company, Robert Benschop Shareholder of: Eli Lilly and Company, Employee of: Eli Lilly and Company, Maria Silk Shareholder of: Eli Lilly and Company, Employee of: Eli Lilly and Company, Stephanie de Bono Shareholder of: Eli Lilly and Company, Employee of: Eli Lilly and Company, Robert Hoffman Shareholder of: Eli Lilly and Company, Employee of: Eli Lilly and Company DOI: 10.1136/annrheumdis-2019-eular.620

\section{THU0213 TRAASVIR STUDY: THROMBOTIC MANIFESTATIONS IN ANTIPHOSPHOLIPID ANTIBODY TRANSIENT POSITIVITY RELATED TO VIRAL INFECTIONS:}

Enrique Esteve-Valverde ${ }^{1}$, Cristina Belizna ${ }^{2}$, Domingo Ruiz-Hidalgo ${ }^{3}$, Jaume Trapé I Pujol ${ }^{4}$, Anna Arnau Bartes ${ }^{5}$, Jaume Alijotas-Reig ${ }^{6} .{ }^{1}$ Internal Medicine Department, Althaia Healthcare University Network of Manresa, Systemic Autoimmune Disease Unit, Manresa, Barcelona, Spain; ${ }^{2}$ Vascular and Coagulation Department, University Hospital Angers, Angers, France; ${ }^{3}$ Internal Medicine Department, Althaia Healthcare University Network of Manresa, Universitat Autònoma Barcelona, Manresa, Barcelona, Spain; ${ }^{4}$ Department of Laboratory Medicine, Althaia Healthcare University Network of Manresa, Barcelona, Spain; ${ }^{5}$ Clinical Research Unit, Althaia Healthcare University Network of Manresa, Manresa, Barcelona, Spain; ${ }^{6}$ Systemic Autoimmune Disease Unit, Department of Internal Medicine, Vall d'Hebron University Hospital, Department of Medicine, Universitat Autonoma Barcelona, Barcelona, Spain

Background: The mollecular pathogenesis of antiphospholipid syndrome is complex (environmental triggers, predisposed individuals). Previous studies suggested that infection may lead to the development of transiently elevated non-thrombogenic aPL antibodies. However, there are increasing case reports of patients with viral infections who develop antiphospholipid antibodies and thromboembolic events.

Objectives: To evaluate the role of acute viral infections in the development of thrombotic events related to aPL transitory (or permanent) positivity.

Methods: We include patients with a current viral infection that was diagnosed before elevated aPL antibodies were identified. One positive laboratory test either $\mathrm{LA}, \mathrm{aCL}$, or anti $\beta 2 \mathrm{GPI}$ antibodies after a prior diagnosis of infection was required ( $<3$ months). Infection must be followed by thromboembolic manifestations (arterial or venous). A time frame of 3 months between infection diagnosis and recognition of aPL antibodies positivity was established. Normal PT and APTT test were observed in all previous patient's blood tests.

Results: From January 2014 to date we have collected 40 cases with a demonstrated acute virosis and an aPL positive result with a thrombotic manifestation. 9 cases (22.5\%) for Epstein-Barr virus, 17 cases (42.5\%) were positive for CMV, $8(20 \%)$ for Parvovirus B19, 3 cases were positive for Influenza A H1N1,3 for HIV, 1 for RSV, 1 for $\mathrm{HCV}$ and 1 case for Rotavirus. Lupus anticoagulant ( $L$ A) positivity was showed in 22 cases $(55 \%)$, 15 cases $(37.5 \%)$ tested positive for $\operatorname{lgM}$ anticardiolipin antibody and 13 cases (32.5\%) also tested positive for IgM anti- $\beta 2 \mathrm{GPI}$ antibodies. Unfortunately, anti-prothrombin antibodies could not been analysed. The clinical manifestations were: leg deep venous thrombosis (17 cases) (42.5\%), pulmonary embolism (5 cases) (12.5\%), superior limbs (3 cases) $(7.5 \%)$ livedoid vasculopathy (3 cases) $(7.5 \%)$, splenic infarction (1 case), ovarian venous thrombosis ( 1 case). Only four arterial thromboses were observed: superior limbs (2 cases), digital ischemia (1case) and transverse myelitis (1 case). We have observed how the IgM virus related antibody became negative and the aPL became negative in parallel in $20 / 40$ cases $(50 \%)$

Conclusion: We hypothesized that thrombotic manifestations of aPLrelated acute viral infections are underdiagnosed, and probably in predisposed host, some viral infections may induce the transient apparition of aPL, mainly those with LA activity with potential pathogenic thrombotic properties.

\section{REFERENCES:}

[1] Miyakis S, Lockshin MD, Atsumi T, Branch DW, Brey RL, Cervera R, et al International consensus statement on an Update of classification criteria for definite antiphospholipid syndrome (APS). J Thromb Haemost. 2006 Feb;4(2):295-306.

[2] Ascer E, Marques M, Gidlund M. M pneumoniae infection, pulmonary thromboembolism and antphospholipid antibodies. BMJ Case Rep. 2011 Apr 19;2011

[3] Abuaf N, Laperche S, Rajoely B, et al. Autoantibodies to phospholipids and to the coagulation proteins in AIDS. Thromb Haemost 1997; 77: 856861.

Disclosure of Interests: None declared

DOI: 10.1136/annrheumdis-2019-eular.3446

\section{THU0214 THE PI3K $\triangle$ SELECTIVE INHIBITOR INCB050465 ABROGATES KIDNEY PATHOLOGY IN A SPONTANEOUS MURINE MODEL OF SYSTEMIC LUPUS ERYTHEMATOSUS}

Brittany Fay, Monika Scuron, Niu Shin, Yan-Ou Yang, Eddy Yue, Andrew Combs, Eduardo Huarte, Melissa Parker, Paul Smith. Incyte Corporation, Wilmington, United States of America

Background: Systemic lupus erythematosus (SLE) is an autoimmune disease that affects multiple organs, including the skin, joints and kidneys. Though SLE typically cycles through periods of flares and remission, patients often eventually succumb to end-stage kidney or cardiovascular damage $^{1}$. SLE is characterized by the presence of autoantibodies that form immune complexes resulting in kidney deposition that significantly contribute to lupus nephritis pathogenesis. Phosphatidylinositol 3-kinases (PI3Ks) are divided into three classes (Class I, II, and III) according to their structure, regulation and substrate specificity. The Class I PI3K delta isoform (PI3K $\delta$ ) has been implicated in autoimmune diseases associated with aberrant B cell and antibody responses. INCB050465 is an oral small molecule $\mathrm{PI} 3 \mathrm{~K} \delta$ selective inhibitor currently being evaluated in clinical trials for the inflammatory indications Sjögren's syndrome and autoim mune hemolytic anaemia (NCT03627065 \& NCT03538041).

Objectives: To quantify the efficacious potential of INCB050465, a selec tive PI3K $\delta$ inhibitor, in a preclinical model of systemic lupus erythematosus with kidney pathology.

Methods: The MRL/lpr mouse model spontaneously develops multiple inflammatory phenotypes that mimic human SLE pathologies, including kidney damage resulting in proteinuria, cutaneous skin lesions and antidouble stranded DNA (anti-dsDNA) antibodies. Kidney sections were stained with hematoxylin and eosin (H\&E) and assigned a composite score based on glomerulus, crescents, protein casts, interstitial inflammation and vasculitis by a rater unaware of the treatment groups ${ }^{2}$. Flow cytometry was performed on splenocytes to characterize $B$ cell and $T$ cell subsets. Anti-dsDNA antibodies were determined by commercial ELISA.

Results: In vitro enzymatic selectivity screening revealed INCB050465 potently inhibited the PI3K $\delta$ kinase enzyme $(\mathrm{IC50}=1.1 \pm 0.5 \mathrm{nM})$, with 20,000-fold selectivity for the other PI3K family member enzymes. Proteinuria identified spontaneous kidney damage in $85 \%+$ of vehicle treated mice by 21 weeks of age, and kidney histology revealed gross tissue enlargement associated with structural abnormalities. In contrast, therapeutic INCB050465 treatment $(0.3-3.0 \mathrm{mg} / \mathrm{kg}$, b.i.d.) dose-dependently reduced the incidence of proteinuria $(p<0.01)$, and kidney structural integrity was normalized ( $p<0.0001$ ). A feature of the MRL/lpr model is lymphocyte hyper-proliferation resulting in lymphadenopathy and splenomegaly. Therapeutic INCB050465 treatment dose-dependently reduced spleen $(p<0.01)$ and lymph node $(p<0.01)$ weight. Cutaneous skin lesions were unaffected by INCB050465 treatment. Splenocyte flow cytometry revealed no reduction in absolute lymphocyte, $\mathrm{CD}_{19^{+}} \mathrm{B}$ cell, $\mathrm{CD}^{+}$or $\mathrm{CD}^{+} \mathrm{T}$ cell frequencies following INCB050465 treatment. However 